\title{
Object play in thick-toed geckos during a space experiment
}

\author{
Valerij Barabanov $^{1} \cdot$ Victoria Gulimova $^{1} \cdot$ Rustam Berdiev $^{2} \cdot$ Sergey Saveliev $^{1}$
}

Received: 26 June 2014/ Accepted: 5 March 2015/Published online: 26 March 2015

(C) Japan Ethological Society and Springer Japan 2015

\begin{abstract}
Play behavior was observed in thick-toed geckos (Chondrodactylus turneri GRAY 1864) during a 30-day orbital experiment on the unmanned spacecraft "BION-M" No. 1. The geckos wore ornamented colored collars which made it possible to track the behavior of individual animals on video recordings. The object of the play behavior was a collar that one of the geckos had managed to remove in the pre-launch period and which floated weightless in the animal holding unit under microgravity. Four of the five geckos participated in play episodes, which were defined as one-time interactions with the collar, as well in a fuller form of play that included approaching the unmoving collar or observing its approach, manipulations with the collar and further tracking the collar. Manipulations with the collar could take the form of complicated play, such as pressing the snout against the edge of the collar rim, multiple episodes of pushing the collar with the snout, inserting the head into the collar, holding the collar by pressing the head to the container floor and tilting the head with the collar on the snout. There were individual variations in play pattern. Explanations for the rarity of play behavior in reptiles under normal conditions and the geckos' playfulness in microgravity are discussed. Appropriate video is available
\end{abstract}

Electronic supplementary material The online version of this article (doi:10.1007/s10164-015-0426-8) contains supplementary material, which is available to authorized users.

Victoria Gulimova

gulimova@yandex.ru

1 Federal State Budgetary Institution "Research Institute of Human Morphology”, ul. Tsurupi-3, Moscow 117418, Russia

2 Research and Educational Center for Wild Animal Rehabilitation, Faculty of Biology, M.V. Lomonosov Moscow State University, Leninskie Gory, 1/12, Moscow 119899, Russia at http://www.momo-p.com/showdetail-e.php? movieid=momo 150224ct01a.

Keywords Play behavior - Thick-toed gecko - Individual marking · Prolonged orbital experiment · Weightlessness

\section{Introduction}

Play behavior is recognized in primates, rodents, carnivores, ungulates, elephants, cetaceans and some birds (Burghardt 2005; Graham and Burghardt 2010). Reptiles have quite a complex brain structure and rather well-developed cognitive and perceptual abilities (Northcutt 2013), but until recently they were considered unable to demonstrate play behavior. Even now, play behavior has been described in sufficient detail and proven in only a few species of reptiles, such as the American alligator (Alligator mississippiensis; Lazell and Spitzer 1977), the Nile soft-shelled turtle (Trionyx triunguis; Burghardt et al. 1996) and monitor lizards (Varanus spp.; Burghardt et al. 2002). The most complete review of play behavior in reptiles to date is that of Burghardt (2005). The primary focus of his review is play behavior in large-bodied reptile species, but he also mentions head-bobbing displays in fence lizards (Roggenbuck and Jenssen 1986), "handwaving" in Australian frillnecked lizards and "wrestling" in African chameleons (Burghardt 1982), although in all of the latter three cases the behavior was observed in neonates, not adults. At the same time, Burghardt (2005) notes that together with his colleagues he has watched neonate, juvenile and adult green iguanas for hundreds of hours in the field and never observed any behavior that seemed playful. Bauer (2013) answered the question "Do geckos play?" with "Probably not, but it is hard to know for 
certain". Thus, the study of play behavior in reptiles is extremely complicated by its rare occurrence and difficulties in setting criteria that make it possible to distinguish play from other forms of behavior (Pellegrini et al. 2007).

The most precise criteria of play behavior still used today, are those proposed by Burghardt (2005). He considered that "play is (1) incompletely functional in the context in which it appears; (2) spontaneous, pleasurable, rewarding or voluntary; (3) differs from other more serious behaviors in form (e.g. exaggerated) or timing (e.g. occurring early in life before the more serious version is needed); (4) is repeated, but not in abnormal and unvarying stereotypic form (e.g. rocking or pacing); (5) is initiated in the absence of severe stress" (Graham and Burghardt 2010).

All of the cases of play behavior in adult reptiles recorded to date have been observed in representatives of large-bodied species and mostly among those in captivity (Burghardt 2005, 2013; Graham and Burghardt 2010). Here, we described our study on play behavior in a smallbodied reptile species, the thick-toed gecko (Chondrodactylus turneri GRAY 1864). We considered thick-toed geckos to be a good animal model for an orbital experiment on an unmanned satellite because: (1) they are able to survive without water and food for a long time; (2) their adhesion ability allows them to stay attached and maintain normal locomotion for the major part of the flight, thus avoiding the stress caused by floating. Prior to our study, we were unable to find any information on play behavior in thick-toed geckos, or any other geckos, under land conditions or on the play behavior of any animal in microgravity. However, previously published data did not rule out the possibility that, despite their small body size, adult thicktoed geckos would show play behavior under the weightless condition that complies with Burghardt's (2005) criteria.

\section{Materials and methods}

The experiment was conducted using adult virgin female thick-toed geckos aged 1.5-2 years under the guidelines for the use of live reptiles in research (approved by Biomedicine Ethics Committee of the Russian Federation State Research Center-Institute of Biomedical Problems, Russian Academy of Sciences/Physiology Section of the Russian Bioethics Committee of Russian Federation National Commission for UNESCO/, minute No. 319 from 4 April 2013). We chose females because male thick-toed geckos can be aggressive towards each other, making it impossible to place more than one male in the same container, and for statistical reasons it was necessary to have more than one gecko in a container. The average weight of the animals was $20.2 \mathrm{~g}$, the average brain weight was $95 \mathrm{mg}$, the average snout-vent length was $8.0 \mathrm{~cm}$ and the average total length was $15.5 \mathrm{~cm}$. Altogether 45 animals were used: 15 animals in the flight experiment (flight group), 15 animals as a delayed synchronous control (DSC group) and 15 animals as a corresponding terrarium control group. The animals of the terrarium control group were housed under laboratory conditions (average day temperature $28{ }^{\circ} \mathrm{C}$, average night temperature $24^{\circ} \mathrm{C}$ ), and the flight group was placed aboard the unmanned spacecraft (SC) "BION-M" No. 1 for 30 days, which was launched on 19 April 2013 and landed on 19 May 2013. Geckos in the DSC group were kept in the laboratory under conditions analogous to those experienced by the flight group.

The geckos of the flight and DSC groups were placed in three containers, respectively, referred to here as the research and support blocks (hereinafter RSB) (Fig. 1), with five females in each RSB. Each RSB had a volume of 5.9 1, the walls were covered with hardboard and the floor was covered with textile laminate. Tube-shelters, one for each gecko in the RSB, made of American oak, were fixed onto the walls. A slot for a revolving-type feeder was constructed in the center of the floor of each RSB, which closed with a plug when not in use. The feeder had ten sections in the form of hollows filled with food for the geckos, i.e. live mealworms (Tenebrio molitor) and a mealworm food mixture that contained bran, dried carrots, crushed egg shell and drinking gel particles. During the flight, the feeder opened for $4 \mathrm{~h}$ every third day, starting on

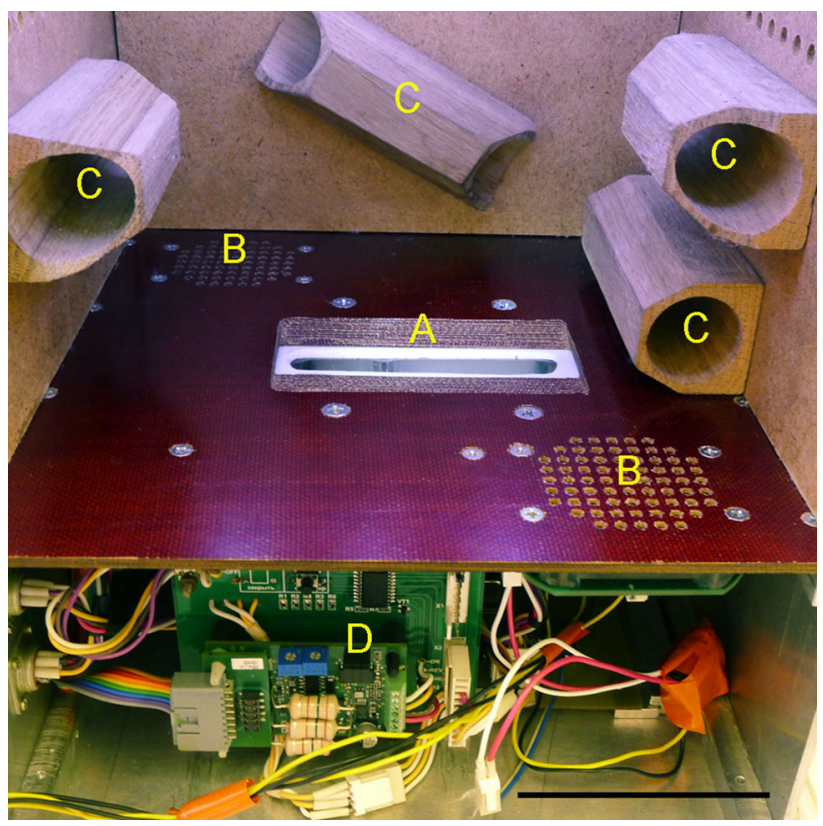

Fig. 1 Research and support block (RSB) with the front wall removed. $A$ Open section of the feeder, $B$ heating zones, $C$ tubeshelters for geckos, $D$ control board. Scale bar: $8 \mathrm{~cm}$ 
the day of launch. There were two heating zones on the floor, each with a diameter of $5 \mathrm{~cm}$; these functioned during the daytime, creating a local temperature of $31-32{ }^{\circ} \mathrm{C}$ on the floor surface. The average temperature on board the satellite during the flight and in the DSC was 21-22 ${ }^{\circ} \mathrm{C}$. There were LEDs, a video camera and a fan on the RSB cover. Light intensity at the bottom of the RSB was on average $485 \mathrm{~lx}$ during the day and $8 \mathrm{~lx}$ at night. The fan was on continuously, and the stream of air was about $3.2 \mathrm{~m}^{3} / \mathrm{h}$. Video recordings were made using a KPCVBN190HDV digital camera (KT\&C Co. Ltd., Seoul, South Korea) and a digital video recorder (TRAL-31-500; SMP-Service).

The geckos in all RSBs were individually marked with colored polyurethane collars. Each collar had a characteristic labeling pattern which allowed individual geckos to be identified even at night when the color of the collar could not easily be determined. Preliminary experiments had shown that the collars are reliable tags and present no safety hazard to the animals in terms of affecting locomotion, foraging behavior or molting.

Play behavior in the thick-toed geckos was detected by chance. Among the 30 geckos marked for the flight and DSC groups, one gecko managed to remove its collar during the 72-h pre-launch period, after the animals had been loaded into the SC. The ventilation in the SC caused the collar to move around the container, bumping against surfaces, tube-shelters and geckos. From time to time, the collar also moved into zones of calm or minimal turbulence where it remained practically motionless for periods ranging from several minutes to several hours.

\section{Results}

The geckos responded to weightlessness by quickly attaching themselves to surfaces, and during their flight they retained not only their attached positions but also normal locomotion, showing normal foraging, exploratory and social behaviors. Social interactions were not radically different from those observed in the land control. There were relatively few of them as the overall activity level reduced during the experiment in space and in the land control. Nevertheless, we did observe smelling and licking of some geckos by others, weak aggression as expressed by a threatening posture and, rarely, pronounced aggression in the form of a fight. From time to time, all of the geckos in a RSB formed a tight group on one of the tube-shelters and stayed there for some time in close tactile contact with each other. We also noted that the presence of the floating collar in RSB No. 2 affected the behavior of the geckos. Initially, the close proximity of the floating collar caused apprehension, watching and avoidance behavior in all geckos.
However, the geckos quickly became familiarized with the floating collar during the early hours of the flight, showing exploratory behavior, as expressed in poking the collar with their snout or licking the collar. During subsequent contacts they sometimes performed play behavior.

Play behavior was demonstrated in its most complete form in the following actions:

1. Having noticed the floating collar, a gecko would watch it approaching and then turn its head or body towards it; alternatively, it would actively approach the more or less unmoving collar.

2. A gecko would carry out various manipulations with the collar.

3. A gecko would watch the collar floating away for some time (tracking).

A total of 66 active (undertaken at the initiative of the gecko) contacts with the collar were identified in the five geckos of RSB No. 2 during the flight. Play behavior was found only in geckos Nos. 1, 3, 4 and 5 (see Figs. 2, 3 and the video at: http://www.momo-p.com/showdetail-e.php?mo vieid=momo150224ct01a). We registered only three active contacts between Gecko No. 6 and the floating collar during the first 6 days of flight, of which no specific play behavior was repeated and only one tracking behavior was registered. Gecko No. 6 demonstrated only exploratory behavior towards the collar. Gecko No. 4 had twice as many contacts with the collar as gecko No.6, and the former continued to show such behavior until the eighth day of the flight. Manipulations of the collar included not only pushes, but also holding it down with the snout and putting the collar on the snout (counter no. 00:35-00:58 in the video image: http://www.momo-p.com/ showdetail-e.php?movieid=momo150224ct01a; ). One repeat behavior was registered, which led us to believe that gecko No. 4 showed play behavior, although it was expressed much more weakly than in the other three geckos.

Play behavior occurred more often and in a more expressive form in geckos Nos. 1, 3 and 5. These geckos were characterized by a high frequency of play episodes, with gecko No. 5 accounting for up to $39.4 \%$ of play episodes. All three geckos displayed a complete form of play behavior. Manipulations of the collar could include relatively short and simple actions, such as a slight touch with the snout or tongue or a single push with the snout, and then the collar would float away. More complex manipulations were also observed, such as pressing the rim of the motionless collar with the snout, resulting in the collar standing on its rim, either rolling around the gecko's snout or sitting on the gecko's snout (Fig. 3; counter No. 01:26-02:43 in the video image: http://www.momo-p.com/ showdetail-e.php?movieid=momo150224ct01a). Repeated pushing of the collar with the snout, inserting the head into the collar hole and holding the collar by pressing the head 


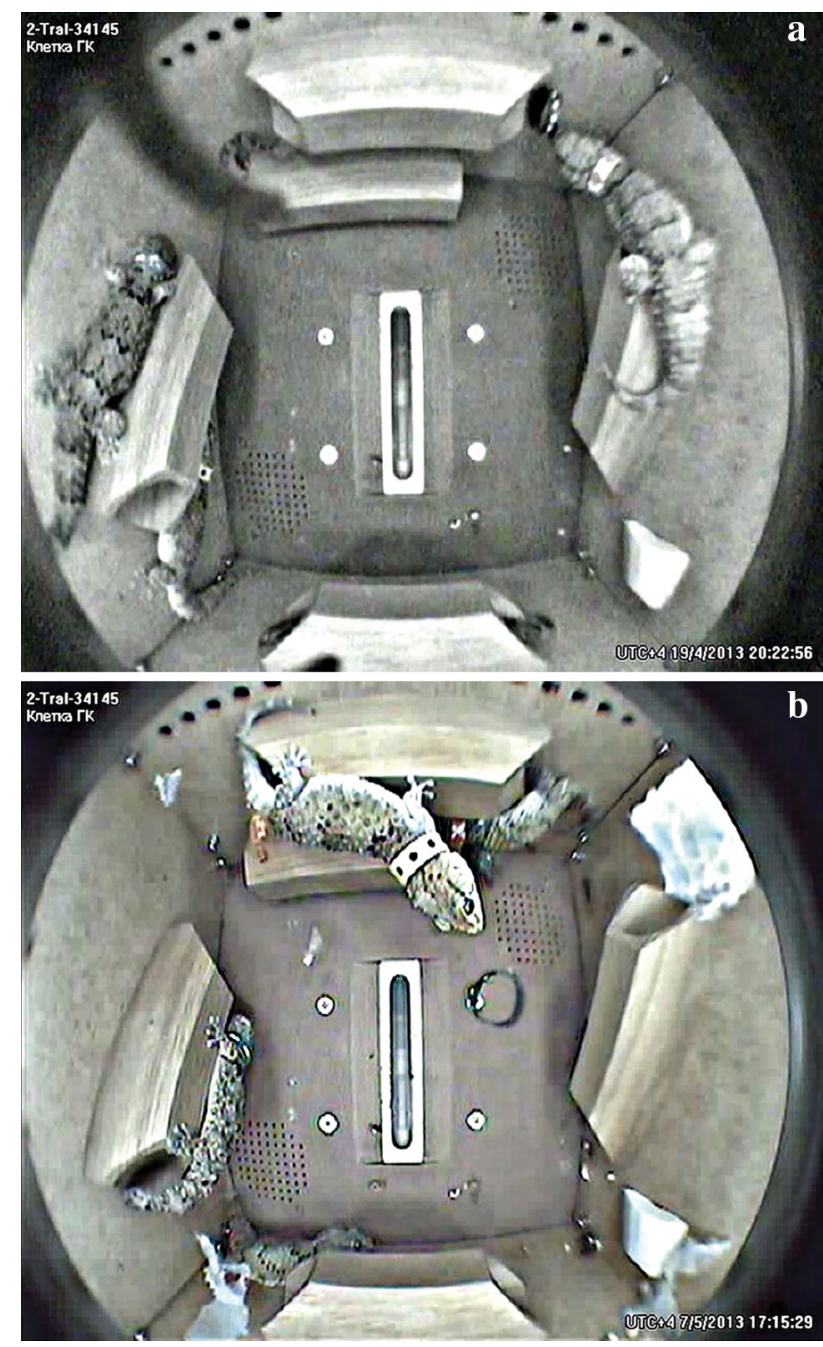

Fig. 2 a Play contact with the floating collar by gecko No. 1 (right in the photograph; red collar with white crosses). Night lighting. b Play contact with the floating collar by gecko No. 5 (top of the photograph; yellow collar with black dots); after making contact with the collar, gecko No. 5 tracked the collar floating away (phase 3). Day lighting. Video images are available at: http://www.momo-p.com/showdetaile.php?movieid=momo150224ct01a, counter nos. 02:46-03:13 (a) and 03:14-03:26 (b). The counter number in the image shows the number of minutes and seconds (mm:ss) from the start of the video recording

to the container floor were observed. A gecko could move its head from side to side with the collar on its snout, and then the collar was tossed slightly or turned around its axis. Simple manipulations were observed much more frequently than complex ones, with the former taking no more than a few seconds to complete. The longest complex play period we observed took $1 \mathrm{~min} 30 \mathrm{~s}$. Both simple play scenes and complex manipulations with the collar were sometimes repeated.

Play activities were observed on the day of launch and continued for 2.5 weeks in geckos Nos. 1 and 3 and until the end of the flight in gecko No. 5 (Fig. 4). It should be noted that a play episode never started if the collar floated past a gecko quickly and occurred very rarely if the collar flew quickly and straight at a gecko (only $4.6 \%$ of all play behavior episodes recorded). Most cases of play behavior were observed when the collar moved slowly ( $57.6 \%$ of all play behavior episodes recorded), with more play behavior episodes when the collar floated slowly onto the gecko (37.9\% of cases) than when it floated slowly past the gecko $(19.7 \%)$. The next most common situation in terms of frequency, typical for the start of a play behavior, was when the collar was either immobile $(27.3 \%)$ or almost immobile (10.6\% of cases) for a total of $37.9 \%$ of all play behavior episodes recorded. There were four play episodes when a gecko purposefully approached the collar to play with it.

Quantitative assessment revealed that the most frequent play behavior type was single contacts with the collar (65.2\% of all contacts). Repeated complex play behavior that consists of different play elements was observed significantly less frequently ( $6.1 \%$ of all contacts), but it was displayed by all three of the most actively playing geckos (Nos. 1, 3 and 5). We note that there was a high frequency of cases where the collar was tracked after a play contact $(69.7 \%)$. A full form of play behavior was revealed in about one-third of all the play episodes (33.3\%). It should also be noted that floating mealworms caused only exploratory behavior in geckos and that floating molting skins caused a behavior similar to play only on rare occasions. Thus, we consider that the numerous manipulations with the collar are indeed elements of play behavior.

\section{Discussion}

The manipulations performed by the geckos with the floating collar do not have an obvious biological rationale. There was no pressure on the geckos to make these manipulations, and the behaviors were repeated, although not in the same way. In addition, the geckos in the flight group did not show any signs of acute or chronic stress at the end of the flight, based on comparisons with the control groups and the video registration data. We consider the geckos' manipulations with the collar not to be a display of predatory behavior for two reasons.

First, with rare exceptions, thick-toed geckos do not perceive floating objects as food, even if these objects are food (i.e. mealworms). We repeatedly observed the behavior of geckos towards floating mealworms and found it basically to be indifference. On occasion, floating worms did elicit investigative behavior (poking with the snout and touching with the tongue), but in 30 days of flight only one gecko among five attempted to catch a floating mealworm: the first attempt was unsuccessful, and in the second time it successfully grabbed the floating worm and ate it (although 

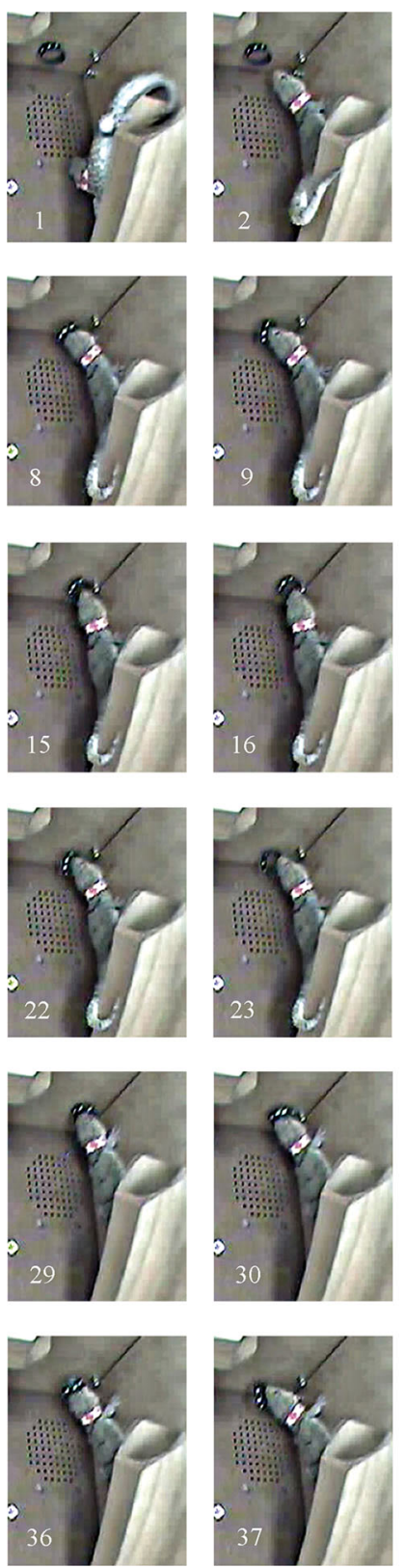
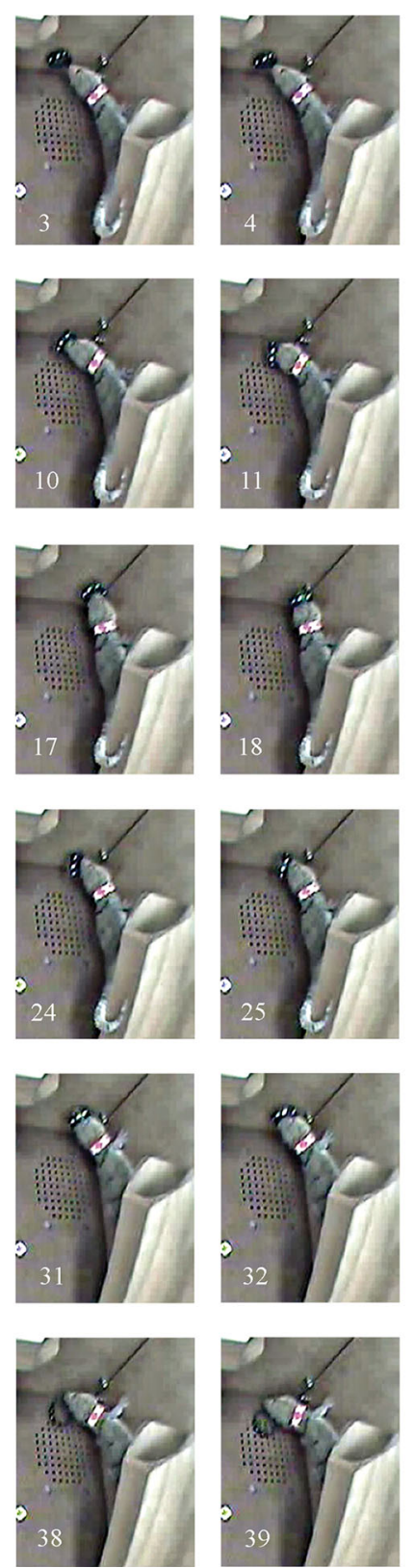
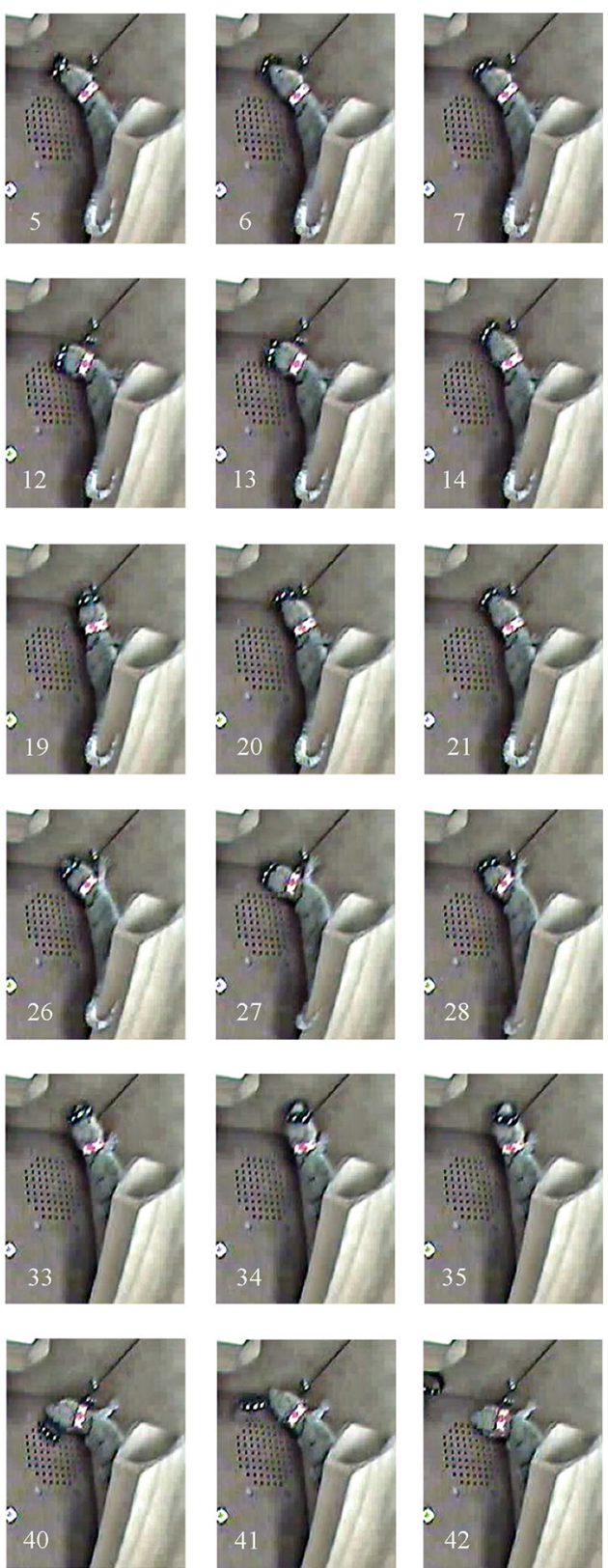

Fig. 3 Storyboard of the most complex and longest play episode in gecko No. 1, fourth day of the flight. Video images are available at: http:// www.momo-p.com/showdetail-e.php?movieid=momo150224ct01a; counter no. 01:26-02:43)

it is important to note that: the worm floated close to the wall and looked like a crawling worm). During the entire space flight all geckos willingly ate mealworms crawling on tube-shelters or walls, with 455 of the $660(68.9 \%)$ worms loaded in the feeder eaten during the flight. This observation suggests that when the geckos felt hungry during the flight they did exercise foraging behavior, but they almost never showed it in relation to floating objects. We never saw any gecko moving a distance comparable to the length of its body to a worm for tactile contact. In contrast, on four occasions a gecko purposefully approached the collar to play with it.
Second, none of the geckos ever tried to grab the collar with its teeth, which is what geckos usually do with food (in the one case when a gecko showed an interest in eating a floating mealworm, he did exactly that). All manipulations with the collar were made with the mouth closed, except for cases of touching with the tongue.

We believe that manipulations of the collar were episodes of play behavior rather than of exploratory behavior as they were repeated many times, including in the middle and towards the end of the flight, by geckos Nos. 1, 3 and 5, when the collar was a familiar object for the geckos. Exploratory behavior in relation to floating mealworms was 
Fig. 4 Number of play episodes in thick-toed geckos during the space flight

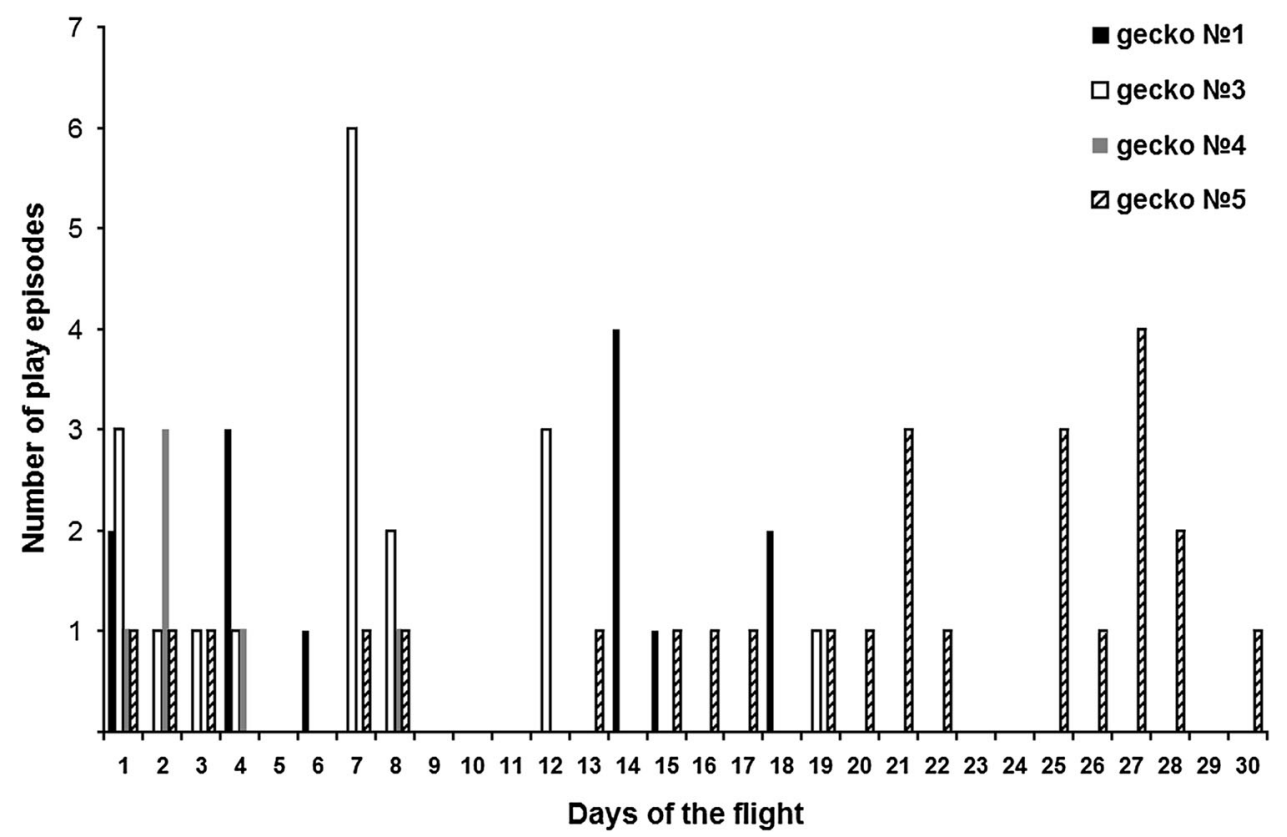

rare and mostly occurred at the beginning of the experiment. In addition, exploratory behavior is characterized by stereotyped actions (Burghardt 2005), whereas the manipulations were variable in our geckos, as shown in the videos.

Play behavior did not occur during each approach of the collar or contact by a certain gecko with it. In a number of situations we observed indifference or avoidance (http://www. momo-p.com/showdetail-e.php? movieid $=$ momo150224ct01a, counter No. 01:14-01:27). It would appear, therefore, that an essential condition for play behavior, in addition to an object of play, is that the gecko is in a suitable mood (state). Play behavior differed individually in the four geckos that showed it in terms of frequency of occurrence and use of play elements.

Thus, the behavior of thick-toed geckos that we observed satisfies Burghardt's (2005) play criteria. The geckos' contacts with or manipulations of the collar were more often observed at the beginning of the experiment than in the second half and towards the end of the flight (Fig. 4). This may be related to both a general decrease in the geckos' behavioral activity at the end of the 1-month flight experience and over-familiarity with the toy (the collar had become boring), similar to the observations of Burghardt et al. (1996) during their study of the Nile softshell turtle.

As we did not observe play behavior under terrestrial conditions in either male or female thick-toed geckos and because our space experiment with prolonged video recording involved female geckos only, we cannot draw a definitive conclusion on whether male geckos can demonstrate play behavior. In one of our previous experiments, a 16-day orbital experiment, we studied a group that included four females and one male, but the duration of the video recording was only $1.8 \%$ of the total flight time, there were no floating objects in the container and the container volume was very small (1.8 1 for 5 geckos). All of these reasons may explain why we did not observe play behavior in either male or female geckos in this experiment (Khvatov et al. 2014).

Based on our results, it would appear that small reptiles can play, but that this ability is individual and depends on the environment. Play behavior is unlikely during the breeding season, in cases of pronounced territorial or aggressive behavior, when the animals are in an uncomfortable environment or under the effects of strong hunger or stress. In the wild, a reptiles' play behavior would usually be energetically unfavorable, which Burghardt explained well using his surplus resource theory (Burghardt 1988), postulating that species with more time and energy resources would play more often (Burghardt 2014). Reptiles differ from mammals in being ectothermic and having a low metabolic rate and a need for a long recuperation period after sustained activity (Burghardt 2005), making them vulnerable to the impact of many environmental factors. These factors were partially or completely eliminated in our experiment. Weightlessness also contributed to a reduction in energy consumption. Thus, our data testify to the validity of the theory of surplus resources.

To summarize, our data suggest that in a suitable habitat even adult small reptiles are capable of performing play behavior. Our results and those of Burghardt (2013) suggest that playfulness may be stimulated in orbital experiments by using an enriched environment. 
Acknowledgments This work was supported by the Autonomous Nonprofit Institution "Institute of Biomedical Problems" (ANO IBP) and the Institute of Biomedical Problems (IBMP), the State Scientific Center of the Russian Federation and Federal State Budgetary Institution of Science (Moscow). We are grateful to the anonymous reviewers for their useful comments, which improved our manuscript. We express our special gratitude to Ivanchenko Dmitry for his excellent assistance in this study.

\section{References}

Bauer AM (2013) Geckos: the animal answer guide. The Johns Hopkins University Press, Baltimore

Burghardt GM (1982) Comparison matters: curiosity, bears, surplus energy and why reptiles don't play. Behav Brain Sci 5:159-160

Burghardt GM (1988) Precocity, play, and the ectotherm-endotherm transition: superficial adaptation or profound reorganization? In: Blass EM (ed) Handbook of behavioral neurobiology. Developmental psychobiology and behavioral ecology, vol 9. Plenum, New York, pp 107-148

Burghardt GM (2005) The genesis of animal play: testing the limits. MIT Press, Cambridge

Burghardt GM (2013) Environmental enrichment and cognitive complexity in reptiles and amphibians: concepts, review, and implications for captive populations. Appl Anim Behav Sci $147: 286-298$
Burghardt GM (2014) A brief glimpse at the long evolutionary history of play. Anim Behav Cognit 1(2):90-98

Burghardt GM, Brian W, Rosscoe R (1996) Problem of reptile play: Environmental enrichment and play behavior in a captive Nile soft-shelled Turtle, Trionyx triunguis. Zool Biol 15:223-238

Burghardt GM, Chiszar D, Murphy JB, Romano J, Walsh T, Manrod J (2002) Behavioral diversity, complexity, and play. In: Murphy J et al (eds) Komodo dragons: biology and conservation. Smithsonian Press, Washington DC, pp 78-117

Graham KL, Burghardt GM (2010) Current perspectives on the biological study of play: signs of progress. Q Rev Biol 85:393-418

Khvatov IA, Gulimova VI, Barabanov VM, Sokolov AYu, Saveliev SV, Kharitonov AN (2014) Peculiar features of the adaptive behavior of thick-toed geckos in the orbital spaceflight experiment. Eksperimental'naya psikhologiya [Exp Psychol (Russia)] 7(3):44-56 (in Russian; English abstract)

Lazell JD, Spitzer NC (1977) Apparent play behavior in an American alligator. Copeia 1977:188-189

Northcutt RG (2013) Variation in reptilian brain and cognition. Brain Behav Evol 82:45-54

Pellegrini AD, Dupuis D, Smith PK (2007) Play in evolution and development. Dev Rev 27:261-276

Roggenbuck ME, Jenssen TA (1986) The ontogeny of display behaviour in Sceloporus undulatus (Sauria: Iguanidae). Ethology 71:153-165 